\title{
The X-ray irradiation reduces the alkaline phosphatase expressed in micro-vessels in rat heart
}

\author{
Author \\ Tomiyasu Koyama \\ Hokkaido University, Sapporo, Japan \\ Email: tomkoyamajp@yahoo.co.jp
}

Number of three capillary portions, $n=10$ rats for each group
BW(g) $\operatorname{LVW}(\mathrm{mg})$ Arteriol. Intermed. Venule. Total

1 hour waiting time after $20 \mathrm{~min} . x$-ray irradiation
Control $181 \pm 3 \quad 429 \pm 29 \quad 438 \pm 69$
$173 \pm 281451 \pm 127$
$2062 \pm 107$

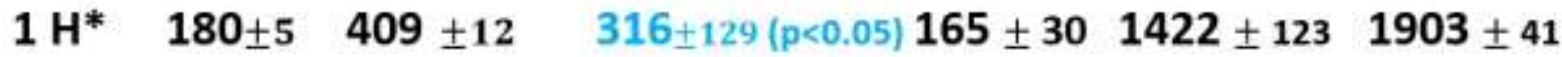

1 wk waiting time after $20 \mathrm{~min}$. X-ray Irradiation
Control $255 \pm 9 \quad 519 \pm 41 \quad 388 \pm 55$
$251 \pm 1121356 \pm 2191995 \pm 91$
1 wk $253 \pm 9 \quad 524 \pm 65$
$140 \pm 33(p<0.01)$
$231 \pm 1021365 \pm 81$
$1736 \pm 93$

3 wk waiting time after $20 \mathrm{~min}$. X-ray irradiation

$\begin{array}{cllllll}\text { Control } & 260 \pm 6 & 531 \pm 95 & 289 \pm 45 & 210 \pm 50 & 1578 \pm 127 & 2077 \pm 57 \\ 3 \text { wk } & 258 \pm 8 & 593 \pm 114 & 138 \pm 18(p<0.01) & 200 \pm 24 & 1349 \pm 146 & 1628 \pm 150(p<0.05)\end{array}$

Left ventricles of 60 male Wistar rats were cut into thin ring shapes, for staining tissue rings and counting of colored capillaries according to Lojda Z(1979). In Lojda's method alcaline phosphatase on arterioles stains blue and DPPIV on venules red.

One hour after the end of 20 minute X-ray irradiation the blue stained capillaries became fainter and significantly reduced in number, as suggested in Table $1 \mathrm{H}^{*}$.

Experimental ( eleven-months-old male Wister rats were exposed to $20 \mathrm{GAy} \mathrm{X}$-ray at a dose of $2 \mathrm{GAy} / \mathrm{min}$. $180 \mathrm{kv} \mathrm{x}-\mathrm{rays}$ filtered by $0.5 \mathrm{~mm} \mathrm{Cu}$ and Al. The rats were readily decapitated with a guillotine at 1 hour, 1 week or 3 weeks after the irradiation.

They were randomly divided into the three groups and killed concomitantly with the irradiated rats at the three time points. Hearts were removed, dripped in o.c.t. compound (Miles Inc. USA), frozen in liquid nitrogen and stored for microscopic observation at $-80^{\circ} \mathrm{C}$.

Rat groups studied, at 20min, mean and \pm SD:

$1 \mathrm{H}^{*}$ : one hour recovery time after 20-min of X-ray-irradiation.

1wk : 1 wk recovery Time,

3 wks : 3 wk recovery time 
Endothelial cells Isolated from the coronary artery, cultured and double stained cells in culture dishes (Horizontal bars $10 \mu \mathrm{m}$ )
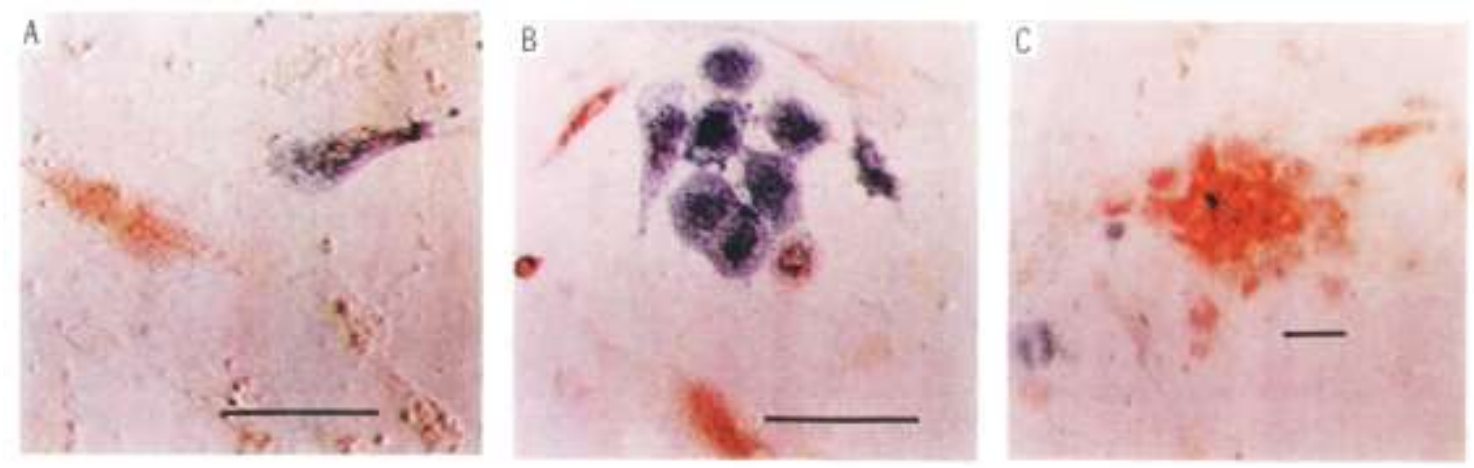

The blue colored cells expressing alkaline phosphatase in arterioles and the red colored cells expressing dipeptidyl peptidase in venules.

Alkaline phosphatase is expressed on the inner or outer surface of arterioles and plays many important enzymatic functions to maintain biological activity.

Conclusion: Alkaline phosphatase is readily destroyed. But usually widely distributed in our body and supports our body function. 


\section{References}

Lojda Z ., Studies on dipepatidylpeptifase IV, Hi1stochem. (1979) 59:153-166.

Batra S, Raksan K, Campbell SE(1991) 41:29-40

Conclusion: Alkaline phosphatase is readily destroyed. But usually widely distributed in our body and supports our body function.

The alkaline phosphatase seems to be fragile but works very hard for us

Different enzyme activities in coronary capillary endothelial cells.

By T.Koyama, M.Gao, T.Uede, S.Batra et al.

Oxygen Transport to Tissue XVIII ed.by Nemoto et LaManna, 1997, 359-364. 